\title{
Building Regional Water-Use Scenarios Consistent with Global Shared Socioeconomic Pathways
}

\author{
Mingtian Yao ${ }^{1}$ (D) Sylvia Tramberend ${ }^{2} \cdot$ Pavel Kabat $^{2}$ • \\ Ronald W.A. Hutjes ${ }^{1}$ - Saskia E. Werners ${ }^{1}$
}

Received: 24 August 2016 / Accepted: 13 December 2016/Published online: 24 December 2016

(C) The Author(s) 2016. This article is published with open access at Springerlink.com

\begin{abstract}
Water use projections are crucial to safeguard sustainable access to freshwater in the future. The Water Futures and Solution initiative (WFaS) has developed a set of global water-use scenarios consistent with the recent Assessment Report framework of the Intergovernmental Panel on Climate Change, notably the Shared Socioeconomic Pathways (SSPs), and applying a hydro-economic classification that links a socioeconomic dimension with hydrologic complexity. Here we present regional water use projections for the Pearl River Delta (PRD) in China consistent with the WFaS global assessment. Using two different downscaling techniques for developing regional water-use scenarios based on the national assumptions made for China in the WFaS assessment, we investigate PRD's water-use projections. The findings indicate significant differences in the PRD's regional development trends compared to China's national SSP. The regionalized scenarios project lower water use because of the PRD's lower share of the manufacturing sector in total Gross Domestic Product (GDP) and higher rates of technological improvement, compared to national development trend assumptions. Nevertheless, hydrological challenges remain for the PRD. Its total water use would still increase by up to $54 \%$ in 2030 under the regionalized scenarios. Although uncertainties related to scarce data remain, we provide a scientifically sound and feasible method to generate regional scenarios that can capture the regional sectorial water uses development as well as being consistent with national water-use scenarios developed by global assessment.
\end{abstract}

Keywords Shared socioeconomic pathways $\cdot$ Regional $\cdot$ Water use $\cdot$ Pearl River Delta $\cdot$ Water futures and solution initiative $\cdot$ Hydro-economic classification

Electronic supplementary material The online version of this article (doi:10.1007/s40710-016-0203-x) contains supplementary material, which is available to authorized users.

Mingtian Yao

mingtian.yao@wur.nl

1 Water System \& Global Change, Wageningen University \& Research, PO Box 47, 6700 AA Wageningen, The Netherlands

2 International Institute for Applied Systems Analysis, Laxenburg, Austria 


\section{Introduction}

Population growth and socio-economic developments have fundamentally changed the drivers of freshwater use by humans (Hoekstra and Chapagain 2007). Over the last few centuries, global human water use has been increasing exponentially as a result of growing food demand and increasing living standards (Vörösmarty et al. 2005). The growing water use is approaching total renewable freshwater availability in many regions, and as a result, freshwater is becoming one of the most limited resources (Wiek and Larson 2012). For future management, both water availability and water-use projections are required to safeguard sustainable access to freshwater to sustain livelihoods, well-being, and socio-economic development (Pahl-Wostl 2007; UN-Water 2013). The impact of socio-economic changes on water use has been assessed by several studies based on conventional global change scenarios (Alcamo et al. 2003b; Alcamo et al. 2007; Oki and Kanae 2006; Vörösmarty et al. 2000). For example, the global socio-economic scenarios of the Special Report on Emission Scenarios (Nakicenovic et al. 2000), or the continental change scenarios like the Water Scenarios for Europe and Neighbouring States (Kamari et al. 2008). Recently, a new set of global change scenarios has been released (Moss et al. 2010). These new scenarios follow a scenario matrix architecture (O'Neill et al. 2014; van Vuuren et al. 2014). The two axes consist of: (1) the level of radiative forcing of the climate system characterised by four different Representative Concentration Pathways (RCPs) (van Vuuren et al. 2011); and (2) a set of alternative futures of societal development, the Shared Socioeconomic Pathways (SSPs) (O'Neill et al. 2015). SSPs and RCPs were independently developed in the context of the Intergovernmental Panel on Climate Change (IPCC) Assessment Report framework (Moss et al. 2010; van Vuuren et al. 2014). Researchers have already started using these scenarios for global water-use assessment with various global hydrological models (Bijl et al. 2016; Hanasaki et al. 2013; Mouratiadou et al. 2016). A recent work was carried out by the Water Futures and Solutions initiative (WFaS; http://www.iiasa.ac.at/WFaS), which is a collaborative, stakeholder-informed effort applying systematic global scenario analysis to identify future hotspots of water insecurity. The WFaS developed a set of water-use scenarios consistent with the SSPs and RCPs, and estimated the global sectorial water use using a state-of-the-art multi-model framework (Wada et al. 2016) (The term "water use" in the WFaS assessment refers to water withdrawal. The present paper adopts this term. Note that water use does not refer to "water consumption", defined as water withdrawal minus return to the river system after usage, e.g. for cooling, irrigation).

The SSP narratives provide five qualitative descriptions (SSP1/2/3/4/5) of conceivable future changes in socio-economic development (e.g., demography, economy and lifestyles, policies and institutions, technology, environment, and natural resources), at the level of large world regions to serve as a basis for integrated scenario analysis. Among the five SSP narratives, the SSP2 world ("Middle of the road") is characterized by development similar to historical trends. The SSP1 world takes the "Green road" towards a more sustainable path, whereas the SSP3 world takes the "Rocky road," with resurgent nationalism and severe challenges for climate mitigation and adaptation. The SSP4 world follows a highly unequal path ("A road divided") with adaptation challenges dominating, while the SSP5 world follows rapid fossil-fuelled development ("Taking the highway") and mitigation challenges dominate (O'Neill et al. 2015). Although its key elements focus on climate policy analysis, the SSPs 
offer the possibility of extending the basic narratives into various dimensions for the analysis of broader sustainable development objectives. In the WFaS initiative, the SSP storylines have been enriched with critical water dimensions that will affect sectorial water uses. This has provided a set of water-extended SSP narratives including qualitative changes in the diverse drivers of societal water use, which were translated into a set of quantitative assumptions for implementation in the multi-model assessment (Wada et al. 2016).

In addition, the WFaS initiative developed a hydro-economic (HE) classification for describing different conditions pertaining to water security. The HE classification links regional hydrologic complexity with the capacity of a country or region to cope with waterrelated risks, both of which have an impact on development and are used to differentiate scenario drivers (Fischer et al. 2015).

However, there are no studies, as yet, investigating whether these global-level scenarios and data are relevant in helping to achieve management goals for regions within countries. Van Ruijven et al. (2014) show that retaining the spatial coherence across different scales while enhancing their applicability is important to improve the usefulness of the SSP scenarios. To assess future sustainability of sectorial water use in large countries like China, understanding the behaviour of water users at the regional level is crucial. Ultimately, national and global sustainable development can only be achieved by the cumulative efforts of each individual region where practical adaptive measurements are employed. Previous research on China's Pearl River Delta (PRD) suggests that a global assessment may be insufficient to reflect future trends of sectorial water uses at a regional scale (Yao et al. 2015). Against this background, in this paper we attempt to address water-use development at a regional level in the near future in a way that is consistent with global socioeconomic scenarios. More specifically, the objective of this study is to propose a scientifically sound and feasible methodology to downscale the scenarios developed for global assessments to capture the development of sectorial water use at a regional level. Key questions include:

1. How can we develop regional water-use scenarios that are consistent with the global SSP storylines and associated national data as well as available regional data?

2. Compared with the national assumptions regarding economic and population growth for China, to what extent do regional narratives and assumptions affect the projected regional sectorial water uses?

3. If the regionalization of global scenarios leads to a different future, which socio-economic factor explains most of this difference?

We selected the PRD as study area for its unique development path in comparison with the rest of the country (Seto et al. 2002), and propose two different approaches to develop wateruse scenarios at the regional level. One follows the assumptions for China from the global assessment. The other adjusts these national assumptions based on PRD's historical development trajectory and current regional development policies. Sectorial water uses under both scenario sets were projected until 2050 using a global water-use model. The analysis compares the resulting estimation of water uses and assesses the impact of regional characteristics on scenario development. By comparing the results from these two scenarios, we then can assess whether the national assumptions generated in the global assessment can capture the regional dynamics in sectorial water uses, and how to develop a regional water-use scenario consistent with global scenarios and socio-economic trends. We discuss the implications of our findings for achieving sustainable water use, the study scope and the data limitations, and finally draw conclusions. 


\section{Methodology}

\subsection{Study Area}

The PRD, located in Guangdong Province, southeast China (Fig. 1), is the area surrounding the Pearl River estuary and includes nine major urban centres. By 2010, the PRD had become the largest urban area in the world with 56 million inhabitants, accounting for $4 \%$ of China's total population and generating $10 \%$ of the country's GDP. More than $80 \%$ of PRD's population lives in cities, whereas China's total urbanization rate is only $50 \%$.

The total annual water use in the PRD is about 25 billion $\mathrm{m}^{3}$, some $4 \%$ of China's overall water use at present. In 2002, industry (comprising manufacturing and electricity generation) was responsible for $42 \%$ of the total water use in the PRD. Since then, industry has surpassed agriculture to become the dominant water user in the area. In 2010, industrial, agricultural and domestic water use accounted for $43 \%, 32 \%$ and $21 \%$ of the total water use, respectively (Water Resources Department of Guangdong Province 2000-2013).

The PRD is among the most water-abundant regions in China, located in the humid subtropical zone and receiving more than $1700 \mathrm{~mm}$ of water in average annual precipitation. Nevertheless, seasonal water shortages have been reported more frequently during the last decade (Tu et al. 2012). The reported water shortages are mainly caused by the severe salt intrusion in the dry season when upstream water abstraction deteriorates the salt-suppressing capacity of the low flow (Chen 2006).

\subsection{Water-Use Model}

In line with the WFaS initiative global assessment, the present study builds on the initial global water scenarios that were developed based on the SSPs and RCPs consistent with the IPCC

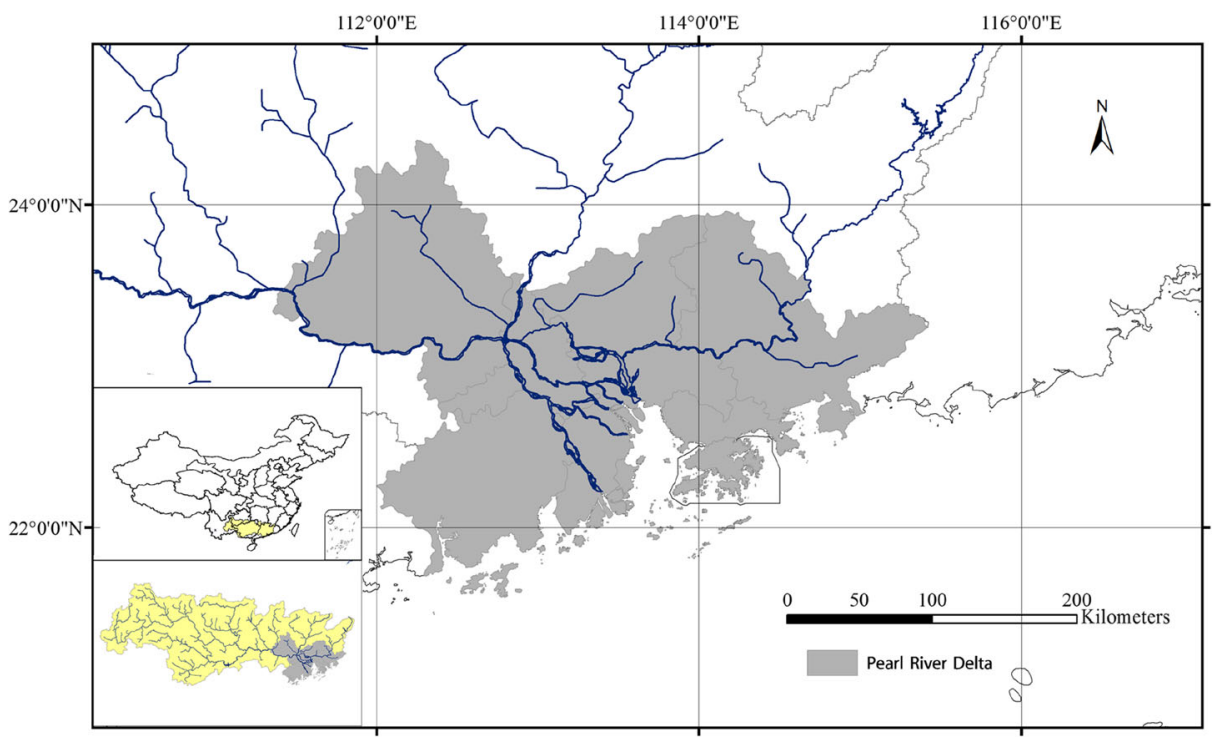

Fig. 1 The Pearl River Delta. The bottom inset shows the location of the delta area in the whole Pearl River Basin, and the one above shows the Pearl River Basin in China 
Assessment Report framework. We selected WaterGAP 2.2 (Flörke et al. 2013; Muller Schmied et al. 2014), one of the global water-use models applied by the WFaS initiative, for the quantification of future pathways of domestic and manufacturing water use in the PRD. A key advantage of WaterGAP is that it disaggregates the industrial sector into water used for cooling in electricity generation and used in the manufacturing sector. In 2010, about $13 \%$ of the total water use in the PRD was for electricity generation, i.e., it accounted for more than a third of the total industrial water use. However, estimating the future dynamics of water use for electricity generation in the PRD is not feasible for the present study because of limited data availability.

WaterGAP (Flörke et al. 2013) estimates manufacturing water use according to equation:

$$
M W U_{t}=\mathrm{MSWI}_{2005} \times M V A_{t} \times T C_{t}
$$

where $\mathrm{MWU}_{\mathrm{t}}$ is the annual manufacturing water use in year $\mathrm{t}$; $\mathrm{MSWI}_{2005}$ is the manufacturing structural water use intensity in the base year 2005; $\mathrm{MVA}_{t}$ is the manufacturing valueadded; and $\mathrm{TC}_{\mathrm{t}}$ is the annual technological change rate for the manufacturing sector.

Estimation of domestic water use (DWU) is achieved in WaterGAP by using population numbers (POP), annual technological change rate (TC), and domestic structural water use intensity (DSWI).

$$
D W U_{t}=\mathrm{DSWI}_{t} \times P O P_{t} \times T C_{t}
$$

The DSWI $\mathrm{t}_{\mathrm{t}}$ represents the change in domestic water-use intensity as result of changes in aspects such as habit or the number of water users. It is represented by a sigmoid curve as a function of the GPD per capita (GDPca) (Alcamo et al. 2003a).

$$
\mathrm{DSWI}=\mathrm{DSWI}_{\min }+\frac{\mathrm{DSWI}_{\max }}{1-e^{-\gamma \cdot G D P_{c a}^{2}}}
$$

A value of $50 \mathrm{~L} /$ person-day was used as $\mathrm{DSWI}_{\text {min }}$ the minimum requirement (Gleick 1996). The maximal domestic structural water use intensity (DSWI $\mathrm{max}_{\text {max }}$ ) and the curve parameter $(\gamma)$ are fitted to the PRD based on its reported water-use records from 2000 to 2010, following a previous study (Yao et al. 2015). The model with calibrated parameters was then validated by the newly released water-use records from 2011 to 2013. The water-use records and socio-economic data are reported by Water Resources Department of Guangdong Province (2000-2013) and Guangdong Statistics Bureau (1991-2014), respectively.

Agricultural water use largely depends on the investment capacity for technological transitions (Wallace 2000). Here, the reported reduction of agricultural water-use intensity (water used per hectare) was used to estimate the effects of technology on agricultural water uses. During 2000-2010, the agricultural water-use intensity of the PRD was reduced by about $2 \%$ annually from $11,475 \mathrm{~m}^{3} /$ ha to $9210 \mathrm{~m}^{3} / \mathrm{h}$, i.e., an annual rate reduction comparable to that of the PRD's industrial water-use intensity (Water Resources Department of Guangdong Province 2000-2013). Thus, we assume that technological transition in the agricultural sector follows a similar rate as in the manufacturing sector.

$$
A W U_{t}=A W U_{2010} \times T C_{t}
$$

where $\mathrm{AWU}_{\mathrm{t}}$ is the future agricultural water use, and $\mathrm{AWU}_{2010}$ is agricultural water use in base year 2010. Data were collected from Guangdong Water Resources Bulletin (Water 
Resources Department of Guangdong Province 2000-2013). TC is the annual technological change rate.

\subsection{Building Scenarios for the Pearl River Delta}

The present study generated two scenario sets for the PRD following the SSP framework, namely SSP-CN and SSP-PRD. Each scenario set contains five scenarios following the original SSPs (SSP1-5). Within each scenario, we investigated four socio-economic dimensions to project the future sectoral water use, i.e., economic development (GDP), population growth, structural GDP changes determined by the share of the manufacturing value-added in the total GDP, and the annual technological change rate.

\subsubsection{Socio-Economic Development}

The first set of scenarios (SSP-CN) follows the national assumptions for China used in the WFaS initiative for the period 2010 to 2050 , thereby reflecting homogenous development in the future across the entire country. The PRD is thus assumed to exhibit the same GDP growth rate and the same contribution of manufacturing to the total GDP as the rest of the country. Today 4.19\% of China's population lives in the PRD, a share assumed to remain constant over time. Quantitative assumptions for China's population and GDP growth were compiled from the SSPs database (www.iiasa.ac.at/web/home/research/researchPrograms/Energy/SSP_Scenario_ Database.html), the IIASA-VIC v9 and OECD Env-Growth v9, respectively. Changes in manufacturing value-added were derived from the UNEP GEO4 Driver Scenarios (distributed by International Futures version 5 at pardee.du.edu) (Rothman et al. 2007).

In reality, however, a region's development trajectory may well be very different compared to the average national development of the country. For instance, a region can benefit from other regions by maximizing the effectiveness of resource utilization and economic development. As China's “youngest" economic engine, the PRD has experienced a unique development path (Seto et al. 2002). To reflect this, the second set of scenarios (SSP-PRD) was constructed within the context of China's overall development, but adjusted the national assumptions from the global WFaS scenarios by taking the region-specific historic trajectories and planning targets into account.

To do this, we first scrutinized available regional projections and development plans. The Pearl River Delta Reform and Development Planning Guideline provides several detailed development targets for the PRD towards 2020 (Pearl River Delta Region Reform and Development Planning Guideline, published by the National Development and Reform Commission in 2008). According to this plan, by 2020, more than 60 million people are expected to live in the PRD. Per capita GDP in the PRD will reach the level of $30,000 \mathrm{US}_{2005}$ (in PPP terms using constant 2005 US dollars), and services will contribute $60 \%$ of the total GDP.

These identified planning targets were used as indicators to adjust the "Middle of the road" SSP2-CN scenario into SSP2-PRD scenario. More specifically:

1. The population under SSP2-PRD is assumed to reach 60 million by 2020 following the current plan. But, as the planned target is limited to 2020, it is difficult to extend the work to the longer-term SSP storyline. Thus, we assume that SSP2-PRD will have the same population growth rate as SSP2-CN during the period of 2020-2050. 
2. During the past few decades, the PRD has experienced economic growth that is unprecedented in China, far above the rest of the country. By 2010, the PRD contributed $9.23 \%$ of China's total GDP. However, convergence of the country's economy is expected due to the more liberalized and open policy under China's "regionally decentralized authoritarian" development regime (Kanbur and Zhang 2005; Xu 2011). As a result, PRD share in national GDP will decline because the rest of China will catch up. Thus, in SSP2-PRD, the PRD's share of GDP in China was adjusted to decrease by $0.25 \%$ every 10 years so that the delta can still meet its target by 2020, which is the GDP per capita of 30,000 US $_{2005}$ proposed in the Pearl River Delta Reform and Development Planning Guideline.

3. In SSP2-PRD, the share of manufacturing gross value-added in total GDP was assumed to follow the historic trend, i.e., decreasing from $47 \%$ in 2010 to $42 \%$ in 2020 and further to $28 \%$ in 2050 .

Next, for the remaining SSP-PRD scenarios (SSP1/3/4/5-PRD), we assume that the PRD will follow a similar development trajectory as in other economies with a comparable socioeconomic status. We used PRD's GDP per capita of the base year 2010, around 15,000 US $\$_{2005}$ per person, and $10 \%$ bandwidth as the indicator to select representative economies in the present world based on World Bank national account data (data.worldbank.org). GDP per capita is a suitable indicator here because: (1) it reflects both total GDP growth and population growth; and (2) it better represents the average level of wealth of a region than the total GDP. In total, nine countries, namely Lithuania, Latvia, Romania, Croatia, Uruguay, Chile, Cuba, Iran, and Kazakhstan, had a GDP per capita in 2010 at the same level as the PRD (i.e., $15,000 \pm 10 \%$ US $\$ 2005$ ). For each of these countries, the national projections of GDP and population under SSP1/3/4/5 were calculated as percentage differences in comparison with the respective SSP2 projection. The average differences across all countries were then applied to SSP2-PRD to quantify GDP development of the SSP1/3/4/5-PRD.

\subsubsection{Technological Improvement}

All three sectorial water uses, agriculture, domestic and manufacturing, are affected by the TC, leading to improvements in water-use efficiency (i.e., output per unit of water), and thereby decreasing water-use intensity (i.e., water use per unit of output in the respective sector). TC estimation is consistent with the WFaS approach, which quantifies annual technological improvement rates for each of the combinations of SSPs and HE classifications using a range of historical observations (Wada et al. 2016).

The HE classification assigns a country or region to a two-dimensional hydro-economic space. In contrast to the scenario space of SSPs, which is defined primarily by the nature of the outcomes, the two dimensions of the HE space are defined based on inputs or elements that led to the outcomes, e.g., GPD per capita and hydrological conditions like total renewable water resource per capita. The Y-dimension proxies the economic and institutional capacity of a country or region to cope with water challenges, and the $\mathrm{X}$-dimension reflects the magnitude and complexity of challenges regarding the management of available water resources. For water scenario development, the HE space is divided into four quadrants, each includes countries characterized by a different level of economic capacity and hydrological challenges (Fischer et al. 2015).

To assign a country or region its HE space, two normalized compound indicators are calculated from a number of component indicators. GDP per capita is used as proxy for 
economic-institutional coping capacity, whereas the hydrological complexity includes four component indicators: (1) total renewable water resources per capita; (2) intensity of water use as ratio of water withdrawal to total renewable water resources; (3) monthly runoff variability; and (4) the dependency of external water resources by measuring the share of external to total renewable water resources.

Details of computing these compound indicators and quantifying the TC in combination with the SSPs storylines can be found in Fischer et al. (2015) and Tramberend et al. (2015). For the present study, TC assumptions for China in the WFaS analysis were deployed in SSP-CN. For the SSP-PRD scenarios, we estimated a region-specified TC for the PRD based on its socio-economic and hydrological conditions by using the HE classification. The same TC is used across all three sectors under each scenario set. Table S1- S4 in the Supplementary Material provide a more detailed overview of the quantitative scenario assumptions.

\subsubsection{Future Water Security}

Over time, countries or regions shift in the two-dimensional space of the HE classification as a result of changing conditions in socio-economic coping capacity (Y-axes) and impacts of climate change on hydrological complexity (X-axes). In the analysis, we explored the trajectory of the location of the PRD in the HE classification, which represented the changing future conditions with respect to water security. The PRD's future HE classification was simulated using: (1) socio-economic and water-use data projected by SSP-PRD; and (2) hydrological conditions (Pearl River discharge and local runoff) simulated by the Variable Infiltration Capacity Model (better known as VIC) for the Pearl River Basin on a $0.5 \times 0.5$ decimal degrees resolution using five Global Climate Models outputs on a daily basis for the period of 2010-2100 under the IPCC scenario RCP4.5 (moderate climate change scenarios) and RCP8.5 (most severe climate change scenarios) (Yan et al. 2015).

The minimal discharge from a graded salt intrusion warning system for the PRD was considered to be the basic environmental flow requirement (Wen and Yang 2006). Surplus discharge from all three tributaries of the Pearl River above this level was considered to be the external renewable water resource for the PRD. The gridded runoff data from the PRD area represented the internal renewable water resources.

Finally, we explored which variable contributed the most to the difference of sectorial water uses between SSP-CN and SSP-PRD. This was achieved using a multiple linear regression and subsequent plotting of model residuals against fitted values (Zuur et al. 2009). Both analyses were conducted in R (R Core Team 2013).

\section{Results}

The results focus on the comparison between the two scenario sets in terms of the characteristic behaviour of sectorial water users under the various scenario assumptions described above. In addition, we explored the potential development of PRD's water security as represented by its HE classification. Please note that hereafter, the term "SSP scenarios" refers to the SSP-CN and SSP-PRD scenarios developed for the present study, rather than the original SSP scenario descriptions (O’Neill et al. 2015). 


\subsection{Linking Global and Regional Scale}

The two scenario families SSP-CN and SSP-PRD illustrate two different downscaling techniques to link the national assumptions for China-developed and applied in the global assessment - with the regional scale of the PRD. Table 1 summarizes the development of socio-economic variables for each of the two scenario sets. By 2050, the PRD is projected to have a larger economy under SSP-CN than under SSP-PRD, with up to $34 \%$ difference in total GDP (SSP1). At the same time, the dependency of GDP growth on the manufacturing sector is projected to increase under SSP-CN, but decrease under SSP-PRD, resulting in a difference between the two of up to $86 \%$ (SSP3). The disagreement between the two scenario sets is caused by the fact that SSP-PRD incorporates regional characteristics into the national assumptions from the global assessment, whereas SSP-CN deploys the national assumptions directly at the regional level. By incorporating the regional characteristics, the socio-economic development projected under SSP-PRD fits better to PRD's historical trend, for example, the share of manufacturing value-added in GDP.

Moreover, as can be seen from Fig. 2, the projection of PRD's potential GDP growth under SSP-PRD is well covered by SSP-CN, especially for the near future. However, the contribution of the manufacturing sector to the total GDP differs strongly between the two sets of scenarios, indicating that the national assumption from the global assessment can capture the overall economic development at a regional level well, but fails to capture the sectorial details, which may lead to significantly different projections for future of water use.

\subsection{Future Water Use}

Figure 3 presents the different trends of future water use projected under the two scenario sets. PRD's annual water use doubles from 21 billion $\mathrm{m}^{3}$ in 2010 to up to 50 billion $\mathrm{m}^{3}$ by 2050 under SSP-CN, but only increases by $14 \%$ on average under SSP-PRD. Under SSP5, the PRD experiences the most water use, which increases by 132\% (SSP-CN) and 57\% (SSP-PRD). SSP-CN scenarios highlight a steep increase of total water use in all five paths, whereas the total water use under SSP-PRD peaks around 2030, then curves in SSP1/2/3/4. SSP5-PRD is an exception, which only manages to stabilize the total water use after 2040. By 2050, SSP5-

Table 1 Socio-economic development in the PRD under two scenario sets

\begin{tabular}{|c|c|c|c|c|c|c|c|c|c|c|}
\hline & \multicolumn{5}{|c|}{ SSP-CN } & \multicolumn{5}{|c|}{ SSP-PRD } \\
\hline & SSP1 & SSP2 & SSP3 & SSP4 & SSP5 & SSP1 & SSP2 & SSP3 & SSP4 & SSP5 \\
\hline \multicolumn{11}{|c|}{ GDP,PPP (billion constant 2005 US\$) } \\
\hline 2010 & 856 & 856 & 856 & 856 & 856 & 843 & 843 & 843 & 843 & 843 \\
\hline 2030 & 3350 & 3076 & 2932 & 3059 & 3624 & 3012 & 2932 & 2825 & 2892 & 3272 \\
\hline 2050 & 6180 & 4719 & 3718 & 4699 & 7509 & 4605 & 4194 & 3638 & 4143 & 5953 \\
\hline \multicolumn{11}{|c|}{ Population (million people) } \\
\hline 2010 & 56.2 & 56.2 & 56.2 & 56.2 & 56.2 & 56.0 & 56.0 & 56.0 & 56.0 & 56.0 \\
\hline 2030 & 56.9 & 57.8 & 58.6 & 56.5 & 56.9 & 58.6 & 60.1 & 61.8 & 58.8 & 58.5 \\
\hline 2050 & 51.3 & 52.9 & 54.8 & 49.6 & 51.3 & 52.0 & 54.9 & 59.0 & 51.5 & 52.0 \\
\hline \multicolumn{11}{|c|}{ Share of manufacturing value added in GDP (\%) } \\
\hline 2010 & 42.6 & 42.6 & 42.0 & 42.6 & 42.6 & 47.5 & 47.5 & 47.5 & 47.5 & 47.5 \\
\hline 2030 & 49.2 & 49.4 & 46.3 & 49.2 & 49.4 & 39.2 & 38.1 & 36.7 & 37.6 & 42.5 \\
\hline 2050 & 48.9 & 49.2 & 46.5 & 48.9 & 49.2 & 31.6 & 28.8 & 25.0 & 28.4 & 40.9 \\
\hline
\end{tabular}




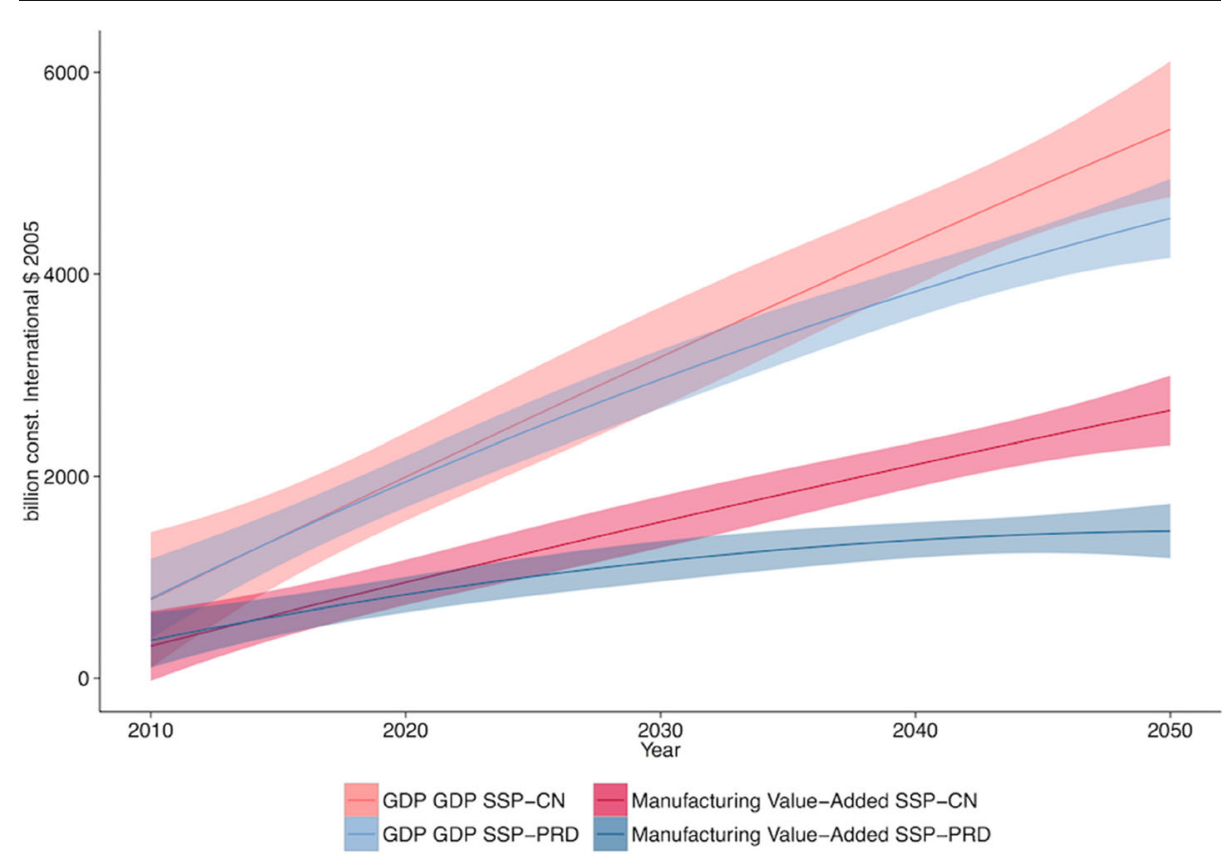

Fig. 2 Comparison of GDP and manufacturing value-added projection under SSP-CN and SSP-PRD

$\mathrm{CN}$ projects the largest net increase of water use among all the scenarios, whereas SSP3-PRD expects a $5 \%$ decrease in total water use.

The dynamics of future water use are largely driven by the manufacturing sector, the only sector where water use increases by 2050 resulting from the increasing GDP. On average, more than $60 \%$ of estimated total water use in 2050 is attributed to the manufacturing sector. SSP5 projects the largest contribution of $81 \%$ (SSP-CN) and 74\% (SSP-PRD).

Water use in all three sectors is affected by different rates of technological improvement under the two sets of scenarios, because of different HE classifications. By 2050, domestic water use will decrease by $30 \%$ (SSP-CN) and 38\% (SSP-PRD) because of the joint effect of technological improvement and a curved population growth. Agricultural water use in this study is affected only by technological improvement, and decreases by $25 \%$ (SSP-CN) and $36 \%$ (SSP-PRD).

\subsection{Water Security in Future}

Figure 4 shows the trajectory of the PRD's HE classification in the coming few decades under different SSPs (economic growth) and climate change scenarios (changing hydrological conditions), in comparison to the current status of China and other selected countries.

The PRD will most likely face increased hydrological challenges even under the most sustainable pathway included in the study, the combination of SSP1 with RCP4.5 scenarios. If the world follows the RCP8.5 scenario and the delta decides to further develop its large economy following SSP5, hydrological conditions in the PRD become more challenging and unstable (see the wiggle curve in Fig. 4). At the same time, the PRD's economic capacity to cope with the potential challenges of hydrological complexity increases rapidly (Fig. 4). This may indicate that despite the increasing hydrological complexity, the PRD is likely to have 

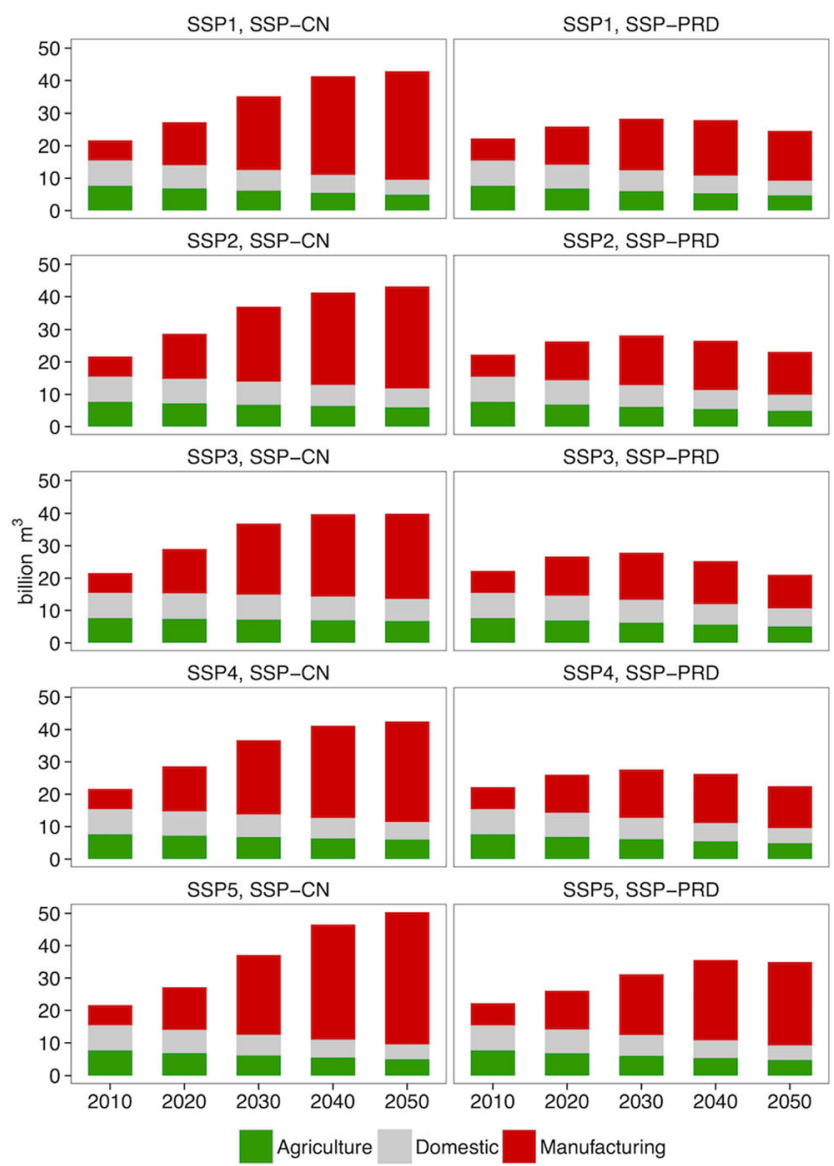

Fig. 3 Sectorial water use projection under different scenarios. The SSP-CN scenario set follows the national assumption for China used in WFaS, the SSP-PRD set contains PRD-specified regional scenarios

enough economic capacity to meet the challenges, provided the economic strength gained over time (as expressed in the proxy variable GDP per capita) is used for efficient management of increasing hydrological challenges and institutional capacity is in place to cope with these challenges.

\subsection{Sensitivity of Variables on Water Use}

The four socio-economic variables used in the present study, GDP, population (POP), share of manufacturing value-added in GDP (MAN) and technological change rate (TC) are investigated using a multiple linear regression to identify the factor most responsible for the large differences in water use under the two scenarios sets (Supplementary Material). In general, for all the five SSPs, differences in the TC contributed the most to the sectorial water use differences between SSP-CN and SSP-PRD. The reason for this may be twofold: (1) TC affects all three sectorial water uses; and (2) the TC of SSP-PRD is faster compared to that of SSP-CN, which follows the assumption of the HE classification from the global analysis. 


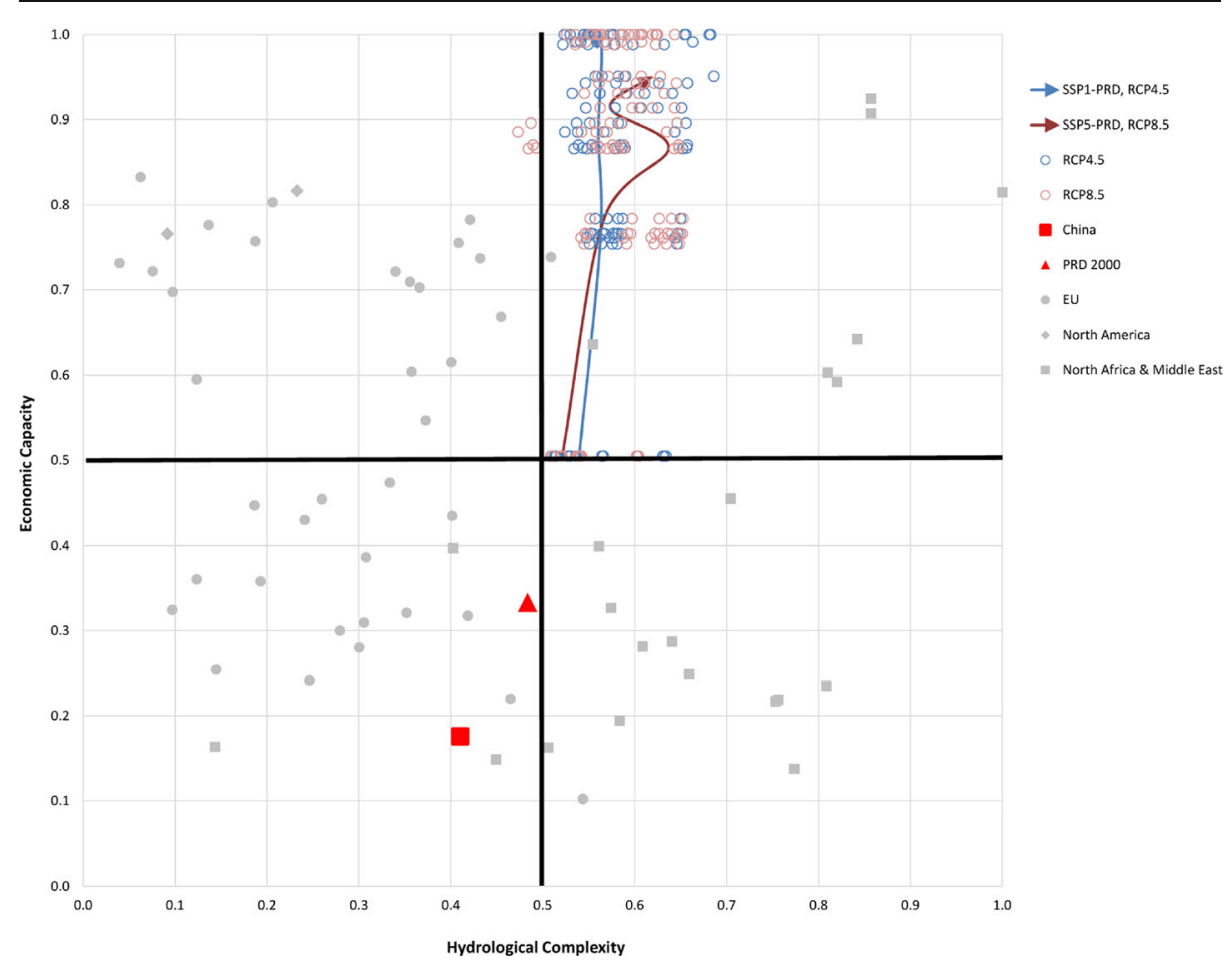

Fig. 4 HE classification of the PRD under different scenarios compared to China and other countries. Blue and red circles are the PRD's HE classification for different SSPs and RCPs projections, from 2010 to 2050 with time steps of 10 years. HE classification for China (red square), PRD (red triangle) and other countries selected (grey shapes) are for the year 2000

Although less influential than overall GDP growth, differences in MAN also contributed. Although POP is one of the main drivers for the total water use, the different population assumptions under the two scenario sets do not lead to significant different total water use by 2050 .

\section{Discussion}

\subsection{Developing Globally Consistent Regional Sscenarios}

Our results indicate that when the development trends of a scenario for China derived from the global assessment are directly applied to the PRD (scenario group SSP-CN), future total water use in the PRD tends to be overestimated, because of regional deviations from the overall development in China (Fig. 3). This suggests that incorporating additional location-specific characteristics is an important step in developing regional scenarios from global information. It is thus of particular importance to develop an informed link between regional projections and the global assessment in the process of downscaling the regional scenarios from national assumptions. In this study, this was achieved by first scrutinizing existing development plans for the PRD and incorporating key features in the scenario group SSP-PRD. The scenario "Middle of the road" SSP2-PRD was first scaled following those plans and the four other SSPs 
were then downscaled applying the same relative relation to SSP2 as the global scenarios. A key strength of this approach is that it is particularly suitable for regions where only a businessas-usual scenario exists.

SSP-CN projects a far larger net increase in water use for manufacturing than SSP-PRD does. This is the result of China's continuously expanding manufacturing sector under all the SSP-CN scenarios, as projected in the global assessment for all emerging economies across the world (Table 1). However, the PRD today is among the most urbanized and industrialized regions in the country. During the last decade, the economic structure has been steadily transforming from industry to services. Thus, following the historic trend, the share of manufacturing value-added in total GDP decreased for all SSP-PRD scenarios.

In addition, the PRD has a very different technological improvement path compared to China (Yao et al. 2015). Being allocated in the right-upper corner of the HE classification we employ here, the PRD has a better economic and institutional starting position for technological improvement compared to many other regions in China. Moreover, the high challenges of the PRD's complex hydrological conditions urge for an implementation of water-saving technologies. The technological improvement in SSP-PRD is thus expected to be significantly faster compared to SSP-CN, especially under SSP3, where the technological improvement rate is three times faster in SSP3-PRD than in SSP3-CN.

Through a shift of the GDP growth from manufacturing to services, combined with a more rapid implementation of technological improvement resulting in higher water use efficiencies, by 2050 the PRD can cut its total water use by $56 \%$ on average in SSP-PRD compared to SSP$\mathrm{CN}$. Thus, regionalization based on regional characteristics is crucial in projecting future socio-economic growth and its impact on future water use at a regional level with global data and information. These results support a previous study by Yao et al. (2015), which concludes that the existing global assessments may generate water use pathways different from the actual development in specific regions of developing countries.

Nevertheless, the PRD is unique in China as the economic development zone attracts enormous investment and policy-support since the beginning of the reform and opening up. Thus, the remarkable difference found between SSP-PRD and SSP-CN may not be seen in the rest of China. That is, if a region's development differs from the PRD but is close to the average national development, SSP-CN may be well able to project the region's future development without need for regionalization.

Building up regional scenarios through a bottom-up procedure following the SSP context may be an alternative way to "downscale" the SSP narratives to the regional level. Such a bottom-up procedure could allow more freedom to incorporate greater numbers of regionspecific variables, possibly resulting in more plausible development projections for that region. Our attempt of applying this bottom-up approach is transferable, especially to those regions with past development paths that differ from their country's. However, it also requires more extensive regional-scale datasets, and preferably a clear long-term development planning target. More participatory efforts from stakeholders and regional experts are also needed to fit the scenarios into the SSPs context, while the improvement to the output remains uncertain.

\subsection{Study Limitations}

Although the bottom-up procedure could generate more region-specific scenarios to better capture future development, it also requires sufficient region-specific variables and data to support the analysis. An important aspect to incorporate, but lacking in our study, is a long- 
term planning target for socio-economic growth in the PRD for the future beyond 2020. Consequently, the ability to capture the region-specific development may be compromised for the long-term projection. For instance, in our study the population in the SSP-PRD after 2020 has the same growth rate as SSP-CN.

The present study is also limited with respect to the sectors it considers. Data limitations for the thermo-electricity sector make it very difficult to associate this sector with the SSP storylines in a consistent way. To assess the future water use in the electricity-generation sector, the key information required include number, type and installed capacity of thermal power plants, and the type of cooling system used. However, none of these are sufficiently available for the study area.

Manufacturing water-use intensity heavily depends on the structural composition of this sector and the corresponding technology it adopts. However, no sub-sector water-use data is available. Thus, sub-sectorial changes within the manufacturing sector cannot be implemented in either this study or in the WFaS global assessment. Moreover, the current results are based on the assumption that future water use will not be limited, i.e., the results would be different if sectoral water use responds to competition over limited water resources. Manufacturing water use, for example, may be limited because available water will first be allocated to domestic water use and food production. This may force the manufacturing sector to improve the water use intensity even under the SSP-CN scenarios. Thus, the current assumption may overstate the difference between the two scenarios.

This study would also benefit from additional analysis of the agricultural sector. The reasons behind the reported improvement in the agricultural water-use intensity are not specified in the report. It may be a mixed effect of changes in technology and climatic conditions. The present study can hardly separate the effects as a result of limited data availability. We can only assess possible improvements from technological changes. Landuse change may also affect agricultural water-use intensity, because of changes in the agricultural production system. For example, replacing open-field vegetable production with highly efficient greenhouses may improve the water use intensity. However, the Integrated Assessment Models for SSPs scenarios have not yet published results for land-use change that include irrigated areas and livestock production systems at the time of this analysis. Although our result shows a decreasing trend of total agricultural water use (Fig. 3), it should be emphasized that this can only be achieved if the water-use intensity in the food production system follows the suggested technological improvement, for example by promoting watersaving irrigation systems. Assessing the impact of future water use from land-use changes is beyond the scope of the present study. However, historic trends reveal a $30 \%$ decline of cultivated land in the PRD from $8460 \mathrm{~km}^{2}$ in 1996 to $5900 \mathrm{~km}^{2}$ in 2007 (Ye et al. 2013). Continuation of this trend will certainly affect the agricultural water use.

Exploring the potential trajectory of the PRD in the HE classification and comparing it to the present world, suggests that after 2030s the PRD will surpass the current economic capacities of countries to invest in and adopt state-of-the-art water saving technologies. We realize that GDP per capita, the vertical axis of the HE plot, is a fairly limited indicator of a country's capacity to adapt to water challenges. More comprehensive methods to assess this adaptive capacity exist, for example, the adaptive capacity wheel (Gupta et al. 2010). Though a full analysis using this framework or inclusion of additional potential indicators (e.g., the corruption perception index, Human Development Index or level of education) is beyond the scope of the present analysis, we believe China, and perhaps even more so the PRD, would score rather high on many of its criteria. However, whether the PRD can maintain the 
suggested fast technological improvement remains uncertain. Lack of incentive to import or invest in new technologies may hamper the PRD's technological advance, especially when other development goals are prioritized over sustainable water management. Moreover, the PRD will face the increasing hydrological challenges caused by climate change, regardless of the potential economic capacities the region can achieve.

Assessing regional water use with global scenarios or data establishes a linkage between regional development and the external environment. Assessing the balance of future water use and the availability of renewable water resources at the regional level needs to be considered for the estimation of realistic growth rates of future water use. These will, in turn, support and help facilitate sustainable water resource management. To further improve the robustness of regional water-use projections consistent with the global assessment, important issues that need to be considered include: (1) refining regionalization of the scenarios narratives and assumptions through a participatory process with regional experts and stakeholders; (2) disaggregating the industrial sector into thermal electricity and sub-manufacturing sectors; and (3) including agricultural land-use change and production-system development.

\section{Conclusion and Outlook}

Scenario analysis provides a sound basis for analysing plausible future developments. Linking scenarios across geographical scales is desirable, because it allows dynamics to be analysed together at different scales. Regional assessments benefit from such linkage in various ways, for example, using global information maintains a scientific credible global context, while providing boundary conditions of the external development environment (Zurek and Henrichs 2007). But, before using the global scenarios at regional level, a downscaling procedure must be followed.

Being a heavily urbanized and industrialized delta area, future water use of the PRD is mostly determined by its economic growth and scale of manufacturing sector. The national assumptions and regionalized water scenarios project the similar overall GDP growth trends, but show large differences in capturing the sectorial dynamics of regional economy, which leads to large differences in water use projections. The regionalized scenarios project a lower water use because, in comparison with national assumptions, the PRD has lower share of the manufacturing sector in total GDP, and higher technological improvement rate.

Nevertheless, hydrological challenges remain for the PRD. Its total water use would still increase by up to $54 \%$ in 2030 under the regionalized scenarios.

The present study provides a scientifically sound and feasible method to derive the input assumptions for regional scenario analysis by linking region-specific historical trends and future development targets with national SSPs scenarios. Using these assumptions, we can generate the regional water scenarios that can capture the regional dynamics in sectorial water uses as well as be consistent with global scenarios and socio-economic trends. Our approach is transferable, especially to those regions that have had different development paths to their country, and preferably have accurate region-specific data regarding socio-economic development and sectoral water uses, and with clear long-term development planning target for future. Our results can be applied to help assess future sustainability of water use at regional levels consistent with state-of-the-art global assessments. 
Acknowledgements This work was supported by the project 'Working with Water: adaptive land use and water management in the Pearl River Delta under climate change and sea level rise' funded by Joint Scientific Thematic Research Programme of the Royal Netherlands Organization for Scientific Research (NWO) under contract number 842.00.002. The funders had no role in study design, data collection and analysis, decision to publish, or preparation of the manuscript. We also appreciate Dr. Martina Flörke for her kind support in data collection and suggestion in finalizing the manuscript.

Open Access This article is distributed under the terms of the Creative Commons Attribution 4.0 International License (http://creativecommons.org/licenses/by/4.0/), which permits unrestricted use, distribution, and reproduction in any medium, provided you give appropriate credit to the original author(s) and the source, provide a link to the Creative Commons license, and indicate if changes were made.

\section{References}

Alcamo J, Doll P, Henrichs T, Kaspar F, Lehner B, Rosch T, Siebert S (2003a) Development and testing of the WaterGAP 2 global model of water use and availability. Hydrol Sci J-J Sci Hydrol 48:317-337

Alcamo J, DÖL1 P, Henrichs T, Kaspar F, Lehner B, RÖSch T, Siebert S (2003b) Global estimates of water withdrawals and availability under current and future "business-as-usual" conditions. Hydrol Sci J 48:339348. doi:10.1623/hysj.48.3.339.45278

Alcamo J, FlÖRke M, MÄRker M (2007) Future long-term changes in global water resources driven by socioeconomic and climatic changes. Hydrol Sci J 52:247-275. doi:10.1623/hysj.52.2.247

Bijl DL, Bogaart PW, Kram T, de Vries BJM, van Vuuren DP (2016) Long-term water demand for electricity, industry and households. Environ Sci Pol 55(Part 1):75-86. doi:10.1016/j.envsci.2015.09.005

Chen Q (2006) Discussion on the policy of inter-regional water transfer to meet the emergency stemming from salty tide in Pearl River basin China. Water \& Wastewater 22:1-4

Fischer G, Hizsnyik E, Tramberend S, Wiberg D (2015) Towards indicators for water security - a global hydroeconomic classification of water challenges. IIASA, Laxenburg

Flörke M, Kynast E, Bärlund I, Eisner S, Wimmer F, Alcamo J (2013) Domestic and industrial water uses of the past 60 years as a mirror of socio-economic development: a global simulation study. Glob Environ Chang 23:144-156. doi:10.1016/j.gloenvcha.2012.10.018

Gleick PH (1996) Basic water requirements for human activities: meeting basic needs. Water Int 21:83-92. doi:10.1080/02508069608686494

Guangdong Statistics Bureau (1991-2014) Guangdong Statistical Yearbook

Gupta J et al (2010) The adaptive capacity wheel: a method to assess the inherent characteristics of institutions to enable the adaptive capacity of society. Environ Sci Pol 13:459-471. doi:10.1016/j.envsci.2010.05.006

Hanasaki N et al (2013) A global water scarcity assessment under shared socio-economic pathways-part 1: water use. Hydrol Earth Syst Sci 17:2375-2391. doi:10.5194/hess-17-2375-2013

Hoekstra AY, Chapagain AK (2007) Water footprints of nations: water use by people as a function of their consumption pattern. Water Resour Manag 21:35-48. doi:10.1007/s11269-006-9039-x

Kamari J, Alcamo J, Barlund I, Duel H, Farquharson F, Florke M, Fry M, Houghton-Carr H, Kabat P, Kaljonen M, Kok K, Meijer KS, Rekolainen S, Sendzimir J, Varjopuro R, Villars N (2008) Envisioning the future of water in Europe - the SCENES project. E-WAter 28:1-28

Kanbur R, Zhang XB (2005) Fifty years of regional inequality in China: a journey through central planning, reform, and openness. Rev Dev Econ 9:87-106. doi:10.1111/j.1467-9361.2005.00265.x

Moss RH et al (2010) The next generation of scenarios for climate change research and assessment. Nature 463: 747-756. doi:10.1038/nature08823

Mouratiadou I et al (2016) The impact of climate change mitigation on water demand for energy and food: an integrated analysis based on the shared socioeconomic pathways. Environ Sci Pol 64:48-58. doi:10.1016/j. envsci.2016.06.007

Muller Schmied H, Eisner S, Franz D, Wattenbach M, Portmann FT, Florke M, Doll P (2014) Sensitivity of simulated global-scale freshwater fluxes and storages to input data, hydrological model structure, human water use and calibration. Hydrol Earth Syst Sci 18:3511-3538. doi:10.5194/hess-18-3511-2014

Nakicenovic N et al (2000) Special report on emissions scenarios: a special report of working group III of the intergovernmental panel on climate change. Cambridge University Press, UK, Cambridge, UK

O’Neill BC et al (2014) A new scenario framework for climate change research: the concept of shared socioeconomic pathways. Clim Chang 122:387-400. doi:10.1007/s10584-013-0905-2 
O'Neill BC et al. (2015) The roads ahead: Narratives for shared socioeconomic pathways describing world futures in the twenty-first century Global Environmental Change (In Press) doi:10.1016/j. gloenvcha.2014.06.004

Oki T, Kanae S (2006) Global hydrological cycles and world water resources. Science 313:1068-1072. doi:10.1126/science. 1128845

Pahl-Wostl C (2007) Transitions towards adaptive management of water facing climate and global change. Water Resour Manag 21:49-62. doi:10.1007/s11269-006-9040-4

R Core Team (2013) R: a language and environment for statistical computing, vol 1. R Foundation for Statistical Computing, Vienna

Rothman DS et al (2007) The future today. In: Magadza C (ed) United Nations environment Programme, global environment outlook GEO 4 environment for development (section E - the outlook-towards 2015 and beyond, chapter 9). UNEP, Nairobi, pp. 397-454

Seto KC, Woodcock CE, Song C, Huang X, Lu J, Kaufmann RK (2002) Monitoring land-use change in the Pearl River Delta using Landsat TM. Int J Remote Sens 23:1985-2004

Tramberend S, Wiberg D, Wada Y, Flörke M, Fischer G, Satoh Y, Yillia P, van Vliet M, Hizsnyik E, Nava LF, Blokker M, Hanasaki N (2015) Building global water use scenarios. IIASA Interim Report. IIASA, Laxenburg, Austria, IR-15-014

Tu XJ, Zhang Q, Singh VP, Chen XH, Liu CL, Wang SB (2012) Space-time changes in hydrological processes in response to human activities and climatic change in the South China. Stoch Env Res Risk A 26:823-834. doi: $10.1007 / \mathrm{s} 00477-011-0516-2$

UN-Water (2013) Water security \& the global water agenda. UN-water analytical brief. United Nations University, Hamilton

van Ruijven BJ et al (2014) Enhancing the relevance of shared socioeconomic pathways for climate change impacts, adaptation and vulnerability research. Clim Chang 122:481-494. doi:10.1007/s10584-013-0931-0

van Vuuren DP et al (2011) The representative concentration pathways: an overview. Clim Chang 109:5-31. doi:10.1007/s10584-011-0148-Z

van Vuuren DP et al (2014) A new scenario framework for climate change research: scenario matrix architecture. Clim Chang 122:373-386. doi:10.1007/s10584-013-0906-1

Vörösmarty CJ, Green P, Salisbury J, Lammers RB (2000) Global water resources: vulnerability from climate change and population growth. Science 289:284-288

Vörösmarty CJ, Lévêque C, Revenga C (2005) Ecosystems and human well-being: current state and trends vol 1. Island Press, Washington

Wada Y et al (2016) Modeling global water use for the twenty-first century: the water futures and solutions (WFaS) initiative and its approaches. Geosci Model Dev 9:175-222. doi:10.5194/gmd-9-175-2016

Wallace JS (2000) Increasing agricultural water use efficiency to meet future food production. Agric Ecosyst Environ 82:105-119. doi:10.1016/s0167-8809(00)00220-6

Water Resources Department of Guangdong Province (2000-2013) Guangdong Water Resource Bulletin

Wen P, Yang X (2006) Evaluation and Analysis of the Salt Tide Early Warning System in the Pearl River Delta in Winter and Spring 2004-2005. Pearl River 3:10-12

Wiek A, Larson KL (2012) Water, people, and sustainability — a systems framework for analyzing and assessing water governance regimes. Water Resour Manag 26:3153-3171. doi:10.1007/s11269-012-0065-6

$\mathrm{Xu} \mathrm{C} \mathrm{(2011)} \mathrm{The} \mathrm{fundamental} \mathrm{institutions} \mathrm{of} \mathrm{China's} \mathrm{reforms} \mathrm{and} \mathrm{development.} \mathrm{J} \mathrm{Econ} \mathrm{Lit} \mathrm{49:1076-1151.}$ doi:10.1257/jel.49.4.1076

Yan D, Werners SE, Ludwig F, Huang HQ (2015) Hydrological response to climate change: the Pearl River, China under different RCP scenarios. Journal of Hydrology: Regional Studies 4(Part B):228-245. doi:10.1016/j.ejrh.2015.06.006

Yao M, Werners SE, Hutjes RWA, Kabat P, Huang H (2015) Sectorial water use trends in the urbanizing Pearl River Delta, China. PLoS One 10:e0115039-e0115039. doi:10.1371/journal.pone.0115039

Ye Y, Zhang H, Liu K, Wu Q (2013) Research on the influence of site factors on the expansion of construction land in the Pearl River Delta, China: by using GIS and remote sensing. Int J Appl Earth Obs Geoinf 21:366373. doi:10.1016/j.jag.2011.10.012

Zurek MB, Henrichs T (2007) Linking scenarios across geographical scales in international environmental assessments. Technol Forecast Soc Chang 74:1282-1295. doi:10.1016/j.techfore.2006.11.005

Zuur AF, Ieno EN, Saveliev AA (2009) Mixed effects models and extensions in ecology with R. Spring Science and Business Media, New York 